Access this article online

Quick Response Code:

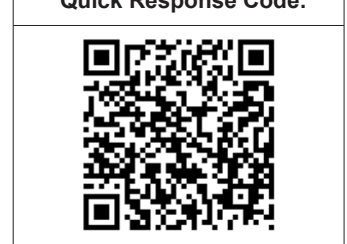

Website:

www.jponline.org

DOI:

10.4103/JLP.JLP_72_17
Department of Pathology, Lokmanya Tilak Municipal Medical College, Mumbai, Maharashtra, India

Address for correspondence: Dr. Sonali Rajesh Saraf, Siddhivinayak

Annexe, Lower Parel, Mumbai - 400013 , Maharashtra, India.

E-mail: sonali0511@ yahoo.com

Submission: 16-04-2017 Accepted: 18-12-2017

\title{
Importance of combined approach of investigations for detection of asymptomatic Hashimoto Thyroiditis in early stage
}

\author{
Sonali Rajesh Saraf, Nitin M. Gadgil, Sheetal Yadav, Alka D. Kalgutkar
}

\begin{abstract}
:
INTRODUCTION: Hashimoto's thyroiditis (HT) is the most common cause of goitrous hypothyroidism in iodine sufficient areas. The diagnosis of $\mathrm{HT}$ is important because it progresses to hypothyroidism, and also, it is associated with thyroid lymphoma and papillary thyroid carcinoma. Apart from thyroid antibodies, assessment of thyroid function test (TFT) levels, ultrasonography (USG), and cytological analysis can help in early diagnosis and management of $\mathrm{HT}$.
\end{abstract}

AIMS AND OBJECTIVES OF THIS STUDY: To know the age incidence and clinical presentation of $\mathrm{HT}$, its association with thyroid hormone levels and with thyroid antibodies and its correlation with the cytologic grade of $\mathrm{HT}$.

MATERIALS AND METHODS: Consecutive convenient method of sampling was adopted at the cytology clinic. Fine-needle aspiration cytology of patients presenting with thyroid enlargement was done using standard technique and aseptic precautions.

RESULTS: Out of 875 cases of thyroid cytology, 134 cases were diagnosed as HT over a 4-year period. A strong female preponderance was observed. A significant proportion of them (103/134) presented in the first four decades of life. Majority of cases (60.63\%) were hypothyroid, while $15.74 \%$ were hyperthyroid and $23.62 \%$ were euthyroid. Apart from thyroid enlargement, although a majority of patients presented with symptoms related to the thyroid, a significant number of patients (38.80\%) were asymptomatic.

CONCLUSIONS: A combined approach of cytological grading of HT along with USG, TFT levels, and thyroid antibodies can detect hypothyroid and subclinical hypothyroid or euthyroid state of HT and provide an appropriate guide to therapy.

Key words:

Asymptomatic, female preponderance, Hashimoto's thyroiditis, subclinical hypothyroid

\section{Introduction}

T Tashimoto's thyroiditis (HT) is the I most common cause of goitrous hypothyroidism in iodine sufficient areas. The diagnosis of HT is important because it progresses to hypothyroidism, and also, it is associated with thyroid lymphoma and papillary thyroid carcinoma. ${ }^{[1]}$ It can also lead to antenatal and neonatal complications in

This is an open access journal, and articles are distributed under the terms of the Creative Commons Attribution-NonCommercial-ShareAlike 4.0 License, which allows others to remix, tweak, and build upon the work non-commercially, as long as appropriate credit is given and the new creations are licensed under the identical terms.

For reprints contact: reprints@medknow.com pregnant patients. Thus, the early diagnosis and correction of HT is very important. Raised levels of thyroid antibodies are the hallmark of HT. The commonly performed investigations such as thyroid function test (TFT), ultrasonography (USG), and fine-needle aspiration cytology (FNAC) of thyroid also aid in the detection of these cases. The aims and objectives of this study were to know the age incidence and clinical presentation of HT, its association with thyroid hormone levels and with thyroid

How to cite this article: Saraf SR, Gadgil NM, Yadav S, Kalgutkar AD. Importance of combined approach of investigations for detection of asymptomatic Hashimoto Thyroiditis in early stage. J Lab Physicians 2018;10:294-8. 
antibodies and also to correlate the grades of HT with thyroid hormone levels and with thyroid antibodies levels. A combined approach of TFT, USG, FNAC, and thyroid antibody levels would help in early detection and management of HT even in patients presenting with euthyroidism or subclinical hypothyroidism.

\section{Materials and Methods}

All patients with thyroid enlargement underwent FNA in cytology clinic. After prior written consent, FNA was done using standard technique and aseptic precautions.

Air-dried slides were stained with Giemsa, and wet slides were fixed with alcohol using hairspray and stained with Papanicolaou stains. Consecutive convenient sampling method was adopted. Cases diagnosed as HT on cytology were included in the study. Detailed clinical history, radiological findings, status of thyroid function (T3, T4, thyroid stimulating hormone [TSH]), and levels of anti-thyroid peroxidase (TPO) antibody were noted.

Criteria used for diagnosis of HT on adequately cellular FNAC smears were mixture of Hurthle cells, lymphoid follicles/lymphocytes in various stages of maturation, and thyroid follicular cells in variable proportion.

As per grading system of Bhatia et al. [Table 1], based on the amount of the lymphocytic infiltrate, HT was categorized in Grade 1, Grade 2, and Grade 3. ${ }^{[2]}$

\section{Observations}

Out of 875 cases who presented with thyroid enlargement for FNAC in the cytology clinic in a 4-year period, 134 cases were diagnosed as HT. A strong female preponderance with female:male of 15.75:1 was observed. Anterior neck swelling was the most common presenting complaint seen in 129 cases. In 5 cases, no obvious thyroid enlargement was seen, so USG-guided FNAC of thyroid was performed because of strong clinical suspicion of HT. Clinical presentation of patients varied from symptoms related to hypothyroidism (e.g., weight gain, menstrual disturbances, facial puffiness, heat intolerance) and those related to hyperthyroidism (e.g., palpitation, tremors, weight loss, menstrual disturbances). Symptoms of weight gain or weight loss were more commonly observed with thyroid enlargement. Although a majority of patients presented with symptoms related to the thyroid, a significant number of patients $(38.80 \%)$ were asymptomatic.

A significant proportion of patients of HT (103/134) were in the first four decades of life, i.e., reproductive age group while 19 of them were in the first two decades of life. Thus, we inferred that female patients of HT in this population have an early onset of the disease. Male patient showed a delayed onset and progression of their disease status.

On local examination, the thyroid gland was observed to be diffusely enlarged in 115 cases $(85.82 \%)$, nodular in 14 cases (10.44\%), and nonpalpable in 5 cases (3.73\%). Cases with nonpalpable thyroid underwent USG-guided FNAC. On USG, out of 134 patients, thyroid gland was found to be diffusely enlarged in 108 cases (80.59\%). Solitary nodular and multiple nodular architecture were observed in 6 and 18 cases, respectively. HT is known to cause diffuse enlargement of the thyroid gland with increased vascularity. However, in few cases, nodular architecture can be seen. The presence of solitary nodule raises the suspicion of malignancy where confirmation by cytological analysis is advisable.

On grading the cases of HT as per Bhatia et al.'s grading system on cytology, ${ }^{[2]}$ varying number of cases in all the 3 grades was observed. Out of 134 cases, most of the cases showed features of Grade II $(n=70)$ HT both in males and females [Table 2]. The older age group (41-70 years) showed mild forms [Figure 1] of the disease (i.e., Grade I and II). Grade III, i.e., severe form of HT was observed in females mainly in the reproductive age group [Figure 2]. This observation indicates the early onset and progression of the disease in the younger age group in females.

The cases with thyroid enlargement which were asymptomatic were seen of Grade I and II severity. These were likely to remain undiagnosed in the early stages if the thyroid enlargement was not adequately investigated.

Table 1: Grading system of Hashimoto's thyroiditis on cytology

\begin{tabular}{ll}
\hline Grade & Morphological features \\
\hline Grade I & $\begin{array}{l}\text { Few lymphoid cells infiltrating the follicles/increased } \\
\text { numbers of lymphocytes in background }\end{array}$ \\
Grade II & $\begin{array}{l}\text { Moderate lymphocytic infiltration or mild lymphocytic } \\
\text { infiltration with Hurthle cell change/giant } \\
\text { cells/anisonucleosis }\end{array}$ \\
Grade III & $\begin{array}{l}\text { Florid lymphocytic inflammation with germinal center } \\
\text { formation, very few thyroid follicular cells left }\end{array}$ \\
\hline
\end{tabular}

Table 2: Correlation of age and grades $(n=134)$

\begin{tabular}{lccccccc}
\hline Age group (years) & \multicolumn{2}{c}{ Grade I } & \multicolumn{2}{c}{ Grade II } & \multicolumn{2}{c}{ Grade III } & Total \\
\cline { 2 - 6 } & Female & Male & Female & Male & Female Male & \\
\hline $0-10$ & 0 & 0 & 1 & 0 & 0 & 0 & 1 \\
$11-20$ & 9 & 0 & 8 & 0 & 2 & 0 & 19 \\
$21-30$ & 19 & 1 & 28 & 1 & 3 & 0 & 52 \\
$31-40$ & 16 & 1 & 13 & 1 & 2 & 0 & 33 \\
$41-50$ & 8 & 0 & 8 & 2 & 0 & 0 & 18 \\
$51-60$ & 2 & 1 & 5 & 1 & 0 & 0 & 9 \\
$61-70$ & 0 & 0 & 2 & 0 & 0 & 0 & 2 \\
Total & 54 & 3 & 65 & 5 & 7 & 0 & 134 \\
\hline
\end{tabular}




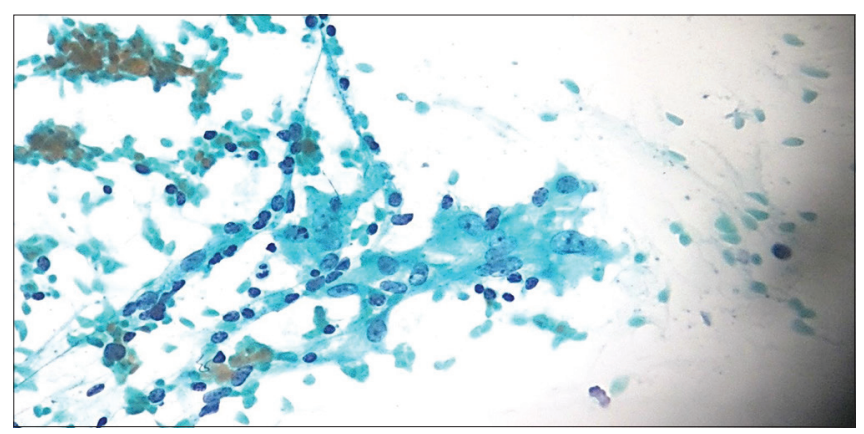

Figure 1: Papanicolaou-stained smear minimal infiltration of thyroid follicles by lymphocytes, $\times 40$

Majority of cases $(60.63 \%)$ were hypothyroid, while $15.74 \%$ were hyperthyroid and $23.62 \%$ were euthyroid. These euthyroid cases need to be clinically identified and subjected for cytological analysis for the diagnosis of HT.

On correlation of cytology grades with TFT levels, it was observed that the probability of development of hypothyroidism rises as the grade of the disease advances [Table 3].

Anti-TPO antibodies levels were analyzed in 105 cases. The levels of anti-TPO antibodies were raised in 82 cases, i.e., $78 \%$ of cases [Table 4 ]. The chances of raised anti-TPO antibodies were seen to be higher as the cytological grade of HT raised and especially in male gender.

As shown in Table 4, out of the total cases of anti-TPO antibody levels studied, a majority of cases had hypothyroidism. Out of 24 cases of euthyroidism, 16 cases had raised TPO antibody levels. This observation suggests that estimation of TPO antibody is an effective tool to diagnose HT, especially in euthyroid cases.

\section{Discussion}

The incidence of HT seems to be increasing in the recent times. It has become ten times more common than it was until the early $1990 \mathrm{~s}^{[3]}$

The increased prevalence, i.e., $15.3 \%$ of HT in this study could be attributed to the coastal location of the study center and the fact that the referral population was broad and representative of an area considered to be iodine sufficient.

The female to male ratio reported in literature for HT ranges from 10:1 to 20:1. ${ }^{[1]}$ This study showed a female preponderance as noted in most of the Indian studies. ${ }^{[4-6]}$ The possible explanation for high female predominance in thyroid autoimmunity might be associated with the $\mathrm{X}$ chromosome containing a number of sex- and immune-related genes which are of key importance in the preservation of immune tolerance. ${ }^{[7]}$

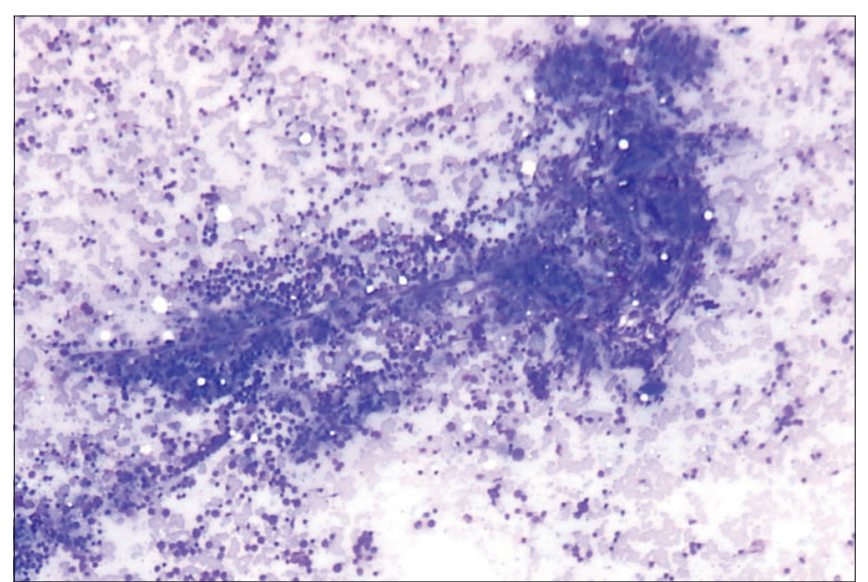

Figure 2: Giemsa-stained smear showing dense infiltration of thyroid follicles by lymphocytes, $\times 10$

Table 3: Correlation of cytology grades with thyroid function test levels $(n=127)$

\begin{tabular}{|c|c|c|c|c|}
\hline Grade & Euthyroid (\%) & Hypothyroid (\%) & Hyperthyroid (\%) & Total \\
\hline Grade I & 18 (33.33) & $23(42.6)$ & $13(24.07)$ & 54 \\
\hline Grade II & $12(18.18)$ & $48(72.72)$ & $6(9.09)$ & 66 \\
\hline Grade III & 0 & $6(85.79)$ & $1(14.28)$ & 7 \\
\hline Total & 30 & 77 & 20 & 127 \\
\hline
\end{tabular}

Table 4: Correlation of anti-thyroid peroxidase antibodies levels with thyroid function test findings $(n=105)$

\begin{tabular}{lccc}
\hline TFT & $\begin{array}{c}\text { Raised anti-TPO } \\
\text { levels }(\%)\end{array}$ & $\begin{array}{c}\text { Normal anti-TPO } \\
\text { levels }(\%)\end{array}$ & Total (\%) \\
\hline Hypothyroid & $51(83.6)$ & $10(16.39)$ & 61 \\
Euthyroid & $16(66.66)$ & $8(33.33)$ & 24 \\
Hyperthyroid & $15(75)$ & $5(25)$ & 20 \\
Total & $82(78.09)$ & $23(21.9)$ & $105(100)$ \\
\hline
\end{tabular}

TFT $=$ Thyroid function test, TPO $=$ Thyroid peroxidase

About $78 \%$ patients of HT were of reproductive age group, i.e., $<40$ years while 19 cases $(14 \%)$ were diagnosed in the first two decades of life. Thus, we inferred that females had an early onset and progression of HT in the population of this study. Since thyroid dysfunction can lead to antenatal and neonatal complications, the diagnosis and correction of any thyroid disorder is very important in pregnant patients. Thyroid autoimmunity is also a risk factor for pregnancy loss. ${ }^{[8]}$ Although a majority of cases presented with an enlarged thyroid and symptoms associated with it, a significant number, i.e., 52 cases $(38.80 \%)$ had only thyroid enlargement without any associated clinical symptoms. This finding correlated with the study by Kudva and Kishore [Table 5]. ${ }^{[9]}$ This data reiterate the fact that some patients of HT may be asymptomatic and few may not have an enlarged thyroid. Five cases did not have an enlarged thyroid but had clinical symptoms suggestive of thyroid disease. These cases are likely to remain unrecognized in the early stages 
Table 5: Comparison of clinical presentation of Hashimoto's thyroiditis

\begin{tabular}{|c|c|c|c|c|c|c|}
\hline & \multicolumn{3}{|c|}{ Present study } & \multicolumn{3}{|c|}{ Kudva and Kishore's study ${ }^{[0]}$} \\
\hline & $\begin{array}{c}\text { Number of } \\
\text { patients }\end{array}$ & Thyroid enlargement & Signs and symptoms & $\begin{array}{c}\text { Number of } \\
\text { patients }\end{array}$ & Thyroid enlargement & Signs and symptoms \\
\hline Grade I & 57 & $56 / 57$ & $\begin{array}{l}\text { 29/57 were } \\
\text { asymptomatic }\end{array}$ & 29 & $23 / 29$ & $25 / 29$ were asymptomatic \\
\hline Grade II & 70 & $66 / 70$ & $\begin{array}{l}22 / 70 \text { were } \\
\text { asymptomatic }\end{array}$ & 14 & $13 / 14$ & $8 / 14$ were asymptomatic \\
\hline Grade III & 7 & $7 / 7$ & $1 / 7$ was asymptomatic & 7 & $7 / 7$ & $4 / 7$ were asymptomatic \\
\hline Total & 134 & 129 & $\begin{array}{l}52 / 134 \text { were } \\
\text { asymptomatic }\end{array}$ & 50 & $43 / 50$ & $37 / 50$ were asymptomatic \\
\hline
\end{tabular}

and may present later with its deleterious effects. Hence, awareness of this condition and proper timely medical care are essential.

On grading HT, using the guidelines laid by Bhatia et al.'s classification, variable results were observed in the different studies. ${ }^{[2,9,6]}$ Most of the patients in this study belonged to Grade II followed by Grade I. This study correlated with study by Kudva and Kishore. ${ }^{[9]}$

As mentioned in literature, ${ }^{[10]}$ majority of cases in this study were hypothyroid (60.62\%). A small proportion of patients, i.e., $15.74 \%$ in this study were hyperthyroid. Hashitoxicosis is a transient hyperthyroid phase of HT. It is due to acute aggravation of thyroid autoimmunity-induced destruction of thyroid follicles. This group of patients may continue to have persistent thyroid dysfunction.

An attempt was made to assess the relation of TFT levels with grading. It was observed that as the grade of HT increases, the probability of hypothyroidism increases. This suggests that the chronicity of the disease increases the chances of hypothyroidism.

Anti-TPO antibody levels were raised in a majority of cases (82 patients - 78.09\%). Our study correlated with study by Rathi et al. ${ }^{[10]}$ Seronegative cases of HT could be explained on the basis of localized antibody production by intrathyroidal lymphocytes. ${ }^{[10]}$ Autoantibodies against $\mathrm{Tg}$ and TPO antigens are clinically most important for diagnosis. A previous study has reported elevation of titers in up to $93 \%$ of the patients. ${ }^{[11]}$ There is a controversy, whether anti-TPO alone is sufficiently reliable to diagnose HT. Up to $20 \%$ adult females with no clinical disease have detectable $\mathrm{Tg} / \mathrm{TPO}$ antibodies, raising the question about their pathogenic significance. ${ }^{[4]}$ Some authors have reported that pregnant euthyroid females who are positive for TPO (antimicrosomal) antibodies and who undergo thyroid hormone therapy may improve their miscarriage rate by $75 \%$ and their premature deliveries rate by $69 \% .^{[12]}$ A higher prevalence of thyroid antibodies also increases the risk of postpartum thyroiditis. ${ }^{[13]}$ Hence, it is suggested that anti-TPO levels along with cytological examination of thyroid are more useful in diagnosing the disease.
Out of 82 patients who were positive for TPO, 51 (62.19\%) were hypothyroid, 15 (18.3\%) were hyperthyroid, and $16(19.5 \%)$ were euthyroid. Similar observations were seen in Shinto and Pachen's study. ${ }^{[14]}$

The relation of TPO antibodies with TFT levels was similar to that of Shinto and Pachen. ${ }^{[14]}$ We conclude that in the euthyroid subgroup, a small percentage of patient tested positive for anti-TPO. Thus, early HT may be missed clinically if FNAC/USG is not performed.

Comparison of anti-TPO and TSH with cytology grades correlated well with the study by Sood and Nigam. ${ }^{[6]}$ Anti-TPO and TSH were elevated in all the three grades but more in Grade III cases. A small proportion of cases had raised TSH with normal TPO levels. In such cases, confirmation of diagnosis by cytology and USG is essential. Cases with raised TPO and normal TSH should have a close follow-up as to avoid deleterious effects of the disease.

\section{Conclusions}

Cytological grading of HT helps in assessing the severity of the disease and can predict the thyroid functional status. As the cytological grade advances, TPO antibodies and hypothyroidism are seen increasingly. HT has an early age onset and progression in females. Since thyroid dysfunction in HT leads to antenatal and neonatal complications, diagnosis and correct management is very crucial in females in reproductive age group. Association of HT with malignancy is also known. Awareness of association of subclinical and clinical hypothyroidism with cardiovascular and neuropsychiatric morbidities makes detection of HT on cytology significant, especially in euthyroid cases. Some patients of HT may be asymptomatic, and few may not have an enlarged thyroid. These cases are likely to remain unrecognized in the early stages and may present later with its deleterious effects. A combined approach of cytological grading of HT along with USG, TFT levels, and thyroid antibodies can detect hypothyroid and subclinical hypothyroid/euthyroid state of HT and provide a guide to its management. 


\section{Financial support and sponsorship}

Nil.

\section{Conflicts of interest}

There are no conflicts of interest.

\section{References}

1. Maitra A. The endocrine system. In: Kumar V, Abbas AK, Aster JC, editors. Robbins and Cotran Pathologic Basis of Disease. $9^{\text {th }}$ ed., Vol. II. Philadelphia: Elsevier Saunders; 2014. p. 1082-105.

2. Bhatia A, Rajwanshi A, Dash RJ, Mittal BR, Saxena AK. Lymphocytic thyroiditis - Is cytological grading significant? A correlation of grades with clinical, biochemical, ultrasonographic and radionuclide parameters. Cytojournal 2007;4:10.

3. Staii A, Mirocha S, Todorova-Koteva K, Glinberg S, Jaume JC. Hashimoto thyroiditis is more frequent than expected when diagnosed by cytology which uncovers a pre-clinical state. Thyroid Res 2010;3:11.

4. Chandanwale SS, Gore CR, Bamanikar SA, Gupta N, Gupta K. Cytomorphologic spectrum of hashimoto's thyroiditis and its clinical correlation: A retrospective study of 52 patients. Cytojournal 2014;11:9.

5. Sreechithra K, Shruthi B, Ajith RD, Narain CD. Cytomorphological features of hashimoto thyroiditis-with sonological and serological findings-analysis of 80 cases. J Evol Med Dent Sci 2014;3:10551-6.
6. Sood N, Nigam JS. Correlation of fine needle aspiration cytology findings with thyroid function test in cases of lymphocytic thyroiditis. J Thyroid Res 2014;2014:430510.

7. Zaletel K, Gaberšček S. Hashimoto's thyroiditis: From genes to the disease. Curr Genomics 2011;12:576-88.

8. Glinoer D. Miscarriage in women with positive anti-TPO antibodies: Is thyroxine the answer? J Clin Endocrinol Metab 2006;91:2500-2.

9. Kudva R, Kishore M. Hashimoto's thyroiditis: A correlation of cytolomorphology with clinical, biochemical \& radiological findings. Int J Sci Res 2015;4:1771-4.

10. Rathi M, Ahmad F, Budania SK, Awasthi S, Kumar A, Dutta S, et al. Cytomorphological aspects of hashimoto's thyroiditis: Our experience at a tertiary center. Clin Med Insights Pathol 2014;7:1-5.

11. Thomas T, Sreedharan S, Khadilkar UN, Deviprasad D, Kamath MP, Bhojwani KM, et al. Clinical, biochemical \& cytomorphologic study on hashimoto's thyroiditis. Indian J Med Res 2014;140:729-35.

12. Unnikrishnan AG, Menon UV. Thyroid disorders in India: An epidemiological perspective. Indian J Endocrinol Metab 2011;15:S78-81.

13. Lazarus JH, Ammari F, Oretti R, Parkes AB, Richards CJ, Harris B, et al. Clinical aspects of recurrent postpartum thyroiditis. Br J Gen Pract 1997;47:305-8.

14. Shinto AS, Pachen L. Prevalence of antithyroid antibodies in histologically proven autoimmune thyroid diseases and correlation with thyroid dysfunction in South India. Thyroid Science 2010;5:1-5. 